'Universidade de Brasília (UnB), Departamento de Sociologia,

Brasília, DF, Brasil

vfpuzone@gmail.com

Vladimir Puzone'

\title{
FILOSOFIA DA HISTÓRIA OU REPRODUÇÃO DA VIDA DOS INDIVÍDUOS? A CRÍTICA DE MAX HORKHEIMER A GEORG LUKÁCS E A REFORMULAÇÃO DO MARXISMO
}

\section{INTRODUÇÃO: A RELAÇÃO DA TEORIA CRÍTICA COM LUKÁCS}

As relações que os autores da assim chamada primeira geração da teoria crítica estabeleceram com uma das obras mais célebres de Georg Lukács (2003), História e consciência de classe, são atravessadas por continuidades e tensões. Por um lado, como a literatura a respeito da teoria crítica reconhece em grande parte, seria impossível pensar a constituição dos trabalhos de Theodor Herbert Marcuse e Max Horkheimer sem a referência imediata aos problemas colocados nos ensaios publicados em i923. Sem descurar da complexidade dos temas tratados nessa obra, que vão desde um exame aprofundado das contradições da filosofia clássica alemã até questões de organização de um partido proletário à época da revolução russa, é possível afirmar que dois temas possuem centralidade para os representantes da Escola de Frankfurt: totalidade e reificação. ${ }^{\text {I }}$ Por outro lado, a despeito da importância das discussões engendradas pela obra de Lukács, seus conceitos e reflexões não foram avaliados de maneira uniforme pela teoria crítica.

Quem manifestou as maiores simpatias pelo livro talvez tenha sido Marcuse. Para ele, seriam admiráveis os aspectos da teoria marxista resgatados por Lukács em sua obra, especialmente a influência que a dialética hegeliana exerceu sobre Marx, assim como a ênfase na consciência e nos fatores subjetivos da revolução. Dessa forma, o marxismo hegeliano de Lukács constituiria uma de suas correntes mais avançadas e exerceria influência decisiva sobre a apropriação da obra marxiana que Marcuse viria a compor. ${ }^{2}$ 
Em contrapartida, tanto Adorno quanto Horkheimer possuem relação bem mais ambivalente com o trabalho do autor húngaro. Com efeito, se considerarmos as obras de Adorno, há pelo menos duas passagens com referências explícitas aos escritos lukácsianos. A primeira encontra-se em um ensaio sobre o realismo literário em Lukács, "Reconciliação extorquida". Adorno destaca a importância dos trabalhos de juventude de Lukács e a ressonância que o conceito de reificação exerceria sobre muitos intelectuais a partir da década de I920. Porém, afirma também que Lukács foi aos poucos cedendo às pressões da doutrina comunista oficial, o que representaria não apenas a negação de seus escritos iniciais, mas também um ajuste progressivo de sua imensa capacidade intelectual (Adorno, 2003: 243).

A segunda passagem de Adorno a respeito de Lukács está presente em Dialética negativa. Ao comentar o primado do objeto para uma dialética materialista, Adorno critica a noção de reificação empregada em História e consciência de classe. Posto que Lukács centra a teoria marxista nesse conceito, ele a aproximaria do idealismo alemão, reduzindo-a a um simples problema subjetivo e tornando-a aceitável para a consciência comum, ou seja, relacionar o termo simplesmente a um problema da consciência afastaria a crítica das determinações objetivas da sociedade sobre os indivíduos. "Não se pode reduzir a dialética nem à reificação, nem a qualquer outra categoria isolada, por mais polêmica que ela seja. Por outro lado, o lamento da reificação evita mais do que denuncia aquilo que produz o sofrimento dos homens. O mal está nas relações que condenam os homens à impotência e à apatia, e que, no entanto, teriam de ser alteradas por eles; e não primariamente nos homens e no modo como as relações aparecem para eles" (Adorno, 2009: I63).

Quanto a Horkheimer, sua ligação com Lukács aparece de forma ainda mais tensionada. ${ }^{3}$ Sem dúvida, as teses de Horkheimer nos anos 30, quando assume a direção do Instituto de Pesquisa Social e se transforma na figura central da teoria crítica no período, constituem-se enquanto prolongamento e reformulação dos problemas lançados originalmente por Lukács e seu conceito de reificação. A caracterização de Lukács a respeito do fenômeno tinha como pano de fundo a constituição da Revolução Russa e seu fracasso na Alemanha e na Hungria. Esse cenário histórico conformou tanto sua teoria a respeito da reificação, que procurava explicar por que os trabalhadores não conseguiam ter clareza das contradições e da crise da sociedade capitalista, quanto à problematização da consciência de classe e à necessidade de um partido proletário que liderasse as massas. ${ }^{4}$ Por sua vez, a cisão entre os trabalhadores alemães após a Primeira Guerra Mundial, divididos entre socialdemocratas e comunistas, e a paulatina ascensão dos movimentos nazifascistas na Europa, marcou para Horkheimer a necessidade de aprofundamento do exame da reificação. ${ }^{5}$ Originalmente formulado por Lukács, o tema serviu para que Horkheimer construísse um programa de investigação teórica e empírica que se traduziu nas publica- 
ções do Instituto de Pesquisa Social e que girava em torno da questão de compreender por que uma parcela considerável dos trabalhadores alemães passou a apoiar o movimento nazista.

De fato, essa influência central é apenas inferida, pois não há qualquer menção explícita de Horkheimer ao livro de Lukács. ${ }^{6}$ Há, contudo, uma exceção, representada por um aforismo que foi excluído da edição final de Dämmerung. Trata-se de "Transfiguração metafísica da revolução". Embora não cite nominalmente Lukács, é possível perceber com nitidez a quem se endereça o pequeno texto. Segundo Horkheimer, haveria naquele período histórico alguns intelectuais que simpatizavam com a revolução por motivos filosóficos, e não por conta da incapacidade de satisfazerem-se as necessidades materiais dos trabalhadores no capitalismo. Tais pensadores acreditavam que este seria o "reino da perfeita pecaminosidade", referência a Teoria do romance, de Lukács. Contra o modo de pensar "racional-calculista" que caracteriza o capitalismo - alusão ao ensaio sobre a reificação e sua apropriação da teoria weberiana da racionalidade capitalista -, eles estariam convencidos de que seria necessária uma transformação na consciência dos seres humanos para que a "verdade eterna" surgisse. "Mas a excentricidade utópica de suas palavras e a inferência de suas exigências idealistas a partir da esfera da superestrutura revelam o caráter idealisticamente religioso dessa radicalidade" (Horkheimer, I985: 264).7 Dessa forma, já na fase inicial de sua obra, Horkheimer expressava reticências acerca da teoria da reificação e que seriam expostas nos trabalhos de Adorno no pós-guerra.

O que propomos neste artigo é reconstituir a crítica de Horkheimer à teoria lukácsiana em História e consciência de classe por meio de textos que, embora não façam referência explícita ao autor húngaro, permitem entender não apenas por que a teoria crítica do período aprofundou o exame da reificação. Além disso, a crítica aos pressupostos da teoria lukácsiana conferiu especificidade ao marxismo empreendido a partir dos trabalhos de Horkheimer nos anos I930, ao mesmo tempo em que detalhava aquilo que no livro de Lukács só aparecia como sugestão: a explicação da derrota das revoluções socialistas deveria passar por uma compreensão sofisticada dos mecanismos que naturalizam as relações sociais capitalistas entre os indivíduos. ${ }^{8} \mathrm{Ou}$, ainda, o trabalho de Lukács representou passo decisivo, mas incompleto, na renovação do marxismo. O passo seguinte seria dado pela teoria crítica.

Certamente, não se pode esquecer que o próprio Lukács (2003: 20-32) empreendeu autocrítica que reconhecia as dificuldades de seu texto. Ainda que o impacto da obra fosse monumental, seu autor apontou para os riscos que a aproximação com algumas das categorias do idealismo alemão implicava para a acuidade de seu diagnóstico acerca do capitalismo. No entanto, temos motivos para acreditar que os comentários de Lukács sobre si mesmo não dão conta inteiramente dos problemas e desdobramentos de História e consciência de classe. Embora a crítica à noção de sujeito-objeto constitua tanto os comentários 
de Lukács quanto os da teoria crítica, esta última trilhou caminhos e análises completamente diferentes. Se o autor húngaro daria importância cada vez maior à formulação de uma ontologia do ser social, Horkheimer e seus colegas de Instituto, orientados por questões históricas distintas, prestaram crescente atenção ao problema do conformismo. Nesse sentido, o entendimento do autor acerca de sua própria obra não esgota os problemas que ela coloca, já que suas formulações possuem autonomia em relação a suas intenções explícitas.

$\mathrm{O}$ aforismo de Horkheimer pode ser visto como uma síntese de sua visão acerca das questões colocadas em História e consciência de classe. Ao mesmo tempo em que condensa o reexame da reificação, especialmente por conta de sua teoria da consciência de classe, o pequeno texto também aponta para a crítica do vínculo estreito entre a obra lukácsiana e o idealismo alemão. A exposição sumária feita por Horkheimer seria retomada em alguns de seus textos do início da década de I930, momento em que o projeto da teoria crítica é lançado e fundamentado. Assim, a análise de certos pressupostos da teoria lukácsiana da reificação e da consciência de classe foi central tanto para a configuração da teoria crítica quanto para que a renovação do marxismo fosse levada a cabo. Ou seja, a revisão de aspectos de História e consciência de classe também permitiria resgatar uma perspectiva diferente e fecunda da obra de Marx, tal como era a pretensão de Lukács. Essa alternativa, que já estava presente naquele livro, diz respeito à superação do esquema base-superestrutura típico do marxismo ortodoxo da primeira metade do século XX. A versão lukácsiana de marxismo ortodoxo e seu conceito de totalidade procuravam contrapor-se a essa visão. ${ }^{9}$ No entanto, somente a partir da crítica de Horkheimer foi possível aprofundar todas as implicações contidas no trabalho do autor húngaro, mas que ficavam limitadas por sua ligação problemática com o idealismo alemão.

Para compreender isso, este artigo toma como eixo duas questões que ajudaram a definir o projeto da teoria crítica em alguns dos textos de Horkheimer do início da década de I930: I) a crítica aos pressupostos hegelianos presentes em História e consciência de classe; 2) a retomada de algumas noções expostas por Marx, sobretudo em A ideologia alemã, que se contrapõem à maneira como Lukács se apropriou da obra marxiana, mas também porque tal recuperação pode ajudar a iluminar alguns aspectos da teoria crítica. Dessa forma, embora tenha ressaltado traços essenciais da sociabilidade capitalista, a crítica de Lukács encontra seus limites em uma aplicação às vezes idealista do marxismo e nas dificuldades em lidar com as transformações históricas do período, que resultaram na aproximação de trabalhadores com o nazifascismo. Não por acaso, a investigação de Horkheimer a respeito desse acontecimento faria diversas alusões aos problemas encontrados na teoria lukácsiana do início dos anos 1920. Em especial uma nova forma de compreender a maneira como os indivíduos reproduzem sua vida cotidiana, embasada nas teses de A ideologia alemã, configuraria o arcabouço explicativo em relação aos problemas 
do conformismo social, indo além do esquema tradicional base-superestrutura. Tal concepção marcaria não somente a teoria crítica em sua fase inicial, mas seria constitutiva de toda a trajetória da Escola de Frankfurt.

\section{A CRÍTICA DE HORKHEIMER: TRANSFIGURAÇÃO E INDIVÍDUO}

Um dos pontos centrais da teoria crítica de Horkheimer em relação à teoria da reificação de Lukács consiste na problematização que o primeiro faz do legado hegeliano para a teoria social em geral e para o marxismo, em particular. $\mathrm{Na}$ primeira metade do século XX, o uso de Hegel esteve no cerne de uma disputa não só teórica, enquanto entendimento do estatuto metodológico do pensamento de Marx, como também política, posto que o lugar ocupado pela dialética hegeliana em relação ao materialismo definiria o marxismo "mais correto" e suas tarefas decorrentes. Por um lado, as teorias da Segunda e Terceira Internacionais se assemelhavam a uma técnica social aplicada. ${ }^{\text {Io }}$ Nesse sentido, elas estariam muito mais próximo de uma ciência da revolução: bastaria conhecer as leis de funcionamento do capitalismo e esperar seus desdobramentos naturais. A aproximação com a filosofia de Hegel seria muito malvista, pois qualquer vínculo com o idealismo, mesmo que de modo negativo, afastaria o marxismo de seu verdadeiro objetivo, o socialismo. Por outro lado, o resgate da herança hegeliana implicava que pensadores como Lukács e Karl Korsch retornassem a um aspecto essencial e então esquecido do marxismo. Tratava-se de ressaltar, no confronto entre Marx e Hegel, o lugar central da história no pensamento desenvolvido pelo primeiro. Dessa forma, o marxismo poderia livrar-se da intransigência que vivia naquele momento.

No entanto, o uso das categorias hegelianas não foi somente o salto qualitativo de Lukács em relação a muitos teóricos marxistas de sua época; apresentou-se também como um de seus problemas centrais. De fato, a partir da incorporação de autores como Hegel e Weber, Lukács pôde resgatar um lado da obra de Marx até então ignorado pela maioria dos marxistas, a teoria do fetichismo. O confronto com a teoria hegeliana também se mostraria fundamental para Horkheimer e não só pela importância do reexame de alguns aspectos da obra do filósofo alemão para renovação da teoria marxista. Além desse traço já ressaltado pelas críticas de Korsch e Lukács às correntes marxistas do início do século XX, estava em questão para Horkheimer dar um passo além dos conceitos de História e consciência de classe, tendo em vista que seus limites decorriam em grande medida da influência de Hegel sobre o revolucionário húngaro. A despeito da importância inequívoca de História e consciência de classe, seus textos transparecem a dificuldade de Lukács em lidar com uma situação histórica na qual as classes trabalhadoras não apenas encontravam dificuldades em constituir uma sociedade emancipada, mas também se incorporavam às hostes fascistas. ${ }^{\text {II }}$ O peso das categorias hegelianas não constituiria um simples acaso. Ao contrário, há estreita afinidade entre esses dois traços da obra lukácsiana. Para enten- 
der como isso ocorre, dois textos de Horkheimer são bastante elucidativos: o discurso de posse no Instituto de Pesquisas Sociais, intitulado "A presente situação da filosofia social e as tarefas de um instituto de pesquisas sociais", e o artigo "Hegel e o problema da metafísica". Embora o diretor do Instituto de Pesquisas Sociais não mencione o nome de Lukács em nenhum dos textos, é possível reconstruir uma crítica aos fundamentos de História e consciência de classe a partir dos comentários de Horkheimer ao filósofo alemão. ${ }^{12}$

Ao descrever as bases do conhecimento para Hegel, Horkheimer comenta a questão da identidade entre sujeito e objeto. Ao mesmo tempo em que Hegel fundamenta o conhecimento metafísico a partir da incondicionalidade do pensamento, isto é, um saber que produza por si mesmo seu sentido e justificação - descartando a atividade concreta dos homens -, ele afirma a necessidade que o conhecimento em sua teoria tem de ser objetivo, ou seja, que a "Ideia" deve se apresentar objetivamente na realidade. Somente um sujeito incondicionado, absoluto, que não esteja limitado por outro ser, pode fundamentar tal saber. Do contrário, esse seria um conhecimento fragmentário. Horkheimer (20I2b: 295) mostra que, na visão hegeliana, “o saber seguro não deve permanece restrito [...] ao conhecimento dos fenômenos psíquicos e físicos; ele recebe fundamentação e objetivo não a partir da vida ativa dos homens, mas é ele que há de trazer à tona, a partir de si mesmo, a justificação e o sentido da vida".

Há aqui uma semelhança entre as teses hegelianas e os argumentos desenvolvidos em História e consciência de classe. A intenção de Lukács ao descrever a relação do proletariado com a sociedade era baseada no conhecimento da totalidade, por meio da categoria "sujeito-objeto", o que o aproxima de Hegel, pois este apontaria na direção de um "saber do todo no sentido de um autoconhecimento do sujeito, que tudo abarca e tudo é" (Horkheimer, 20I2b: 297). A diferença principal é que, enquanto Hegel interpretava a realização do autoconhecimento como o desenvolvimento da história humana, por meio das mais altas realizações da cultura e do Estado, Lukács atribuía o autoconhecimento a uma classe, e não a uma instância guiada pela "astúcia da razão".

Com o proletariado, o sujeito e o objeto da história não apareceriam mais de forma duplicada, como para a burguesia. Como a reificação atinge até mesmo sua individualidade, não haveria a ilusão própria aos burgueses da possibilidade de se imaginar sujeito dos acontecimentos. "Desse modo, para o trabalhador, o caráter reificado da manifestação imediata da sociedade capitalista é levado ao extremo" (Lukács, 2003: 336). As dificuldades de História e consciência de classe começam quando Lukács tenta estabelecer o salto para passar de uma posição a outra, identificando o sujeito do processo de produção com seu objeto. Certamente, o proletariado só pode tornar-se consciente de seu ser social se tiver a consciência de que ele também é uma mercadoria, a autoconsciência do objeto. O lado "sujeito" da equação aparece porque ele próprio é o 
produtor das mercadorias, o sujeito da produção capitalista. Mas a percepção de que ele mesmo é condicionado pela coisificação não é dada de antemão. Por isso, há uma tendência no livro a destacar as premissas para a unificação de sujeito e objeto, a passagem da mera contemplação à ação, "da classe 'contra o capital' à classe para si mesma" (Lukács, 2003: IOI).

À primeira vista, o idealismo hegeliano é posto de cabeça para baixo em História e consciência de classe, pois o "desenvolvimento da Ideia" é substituído por um agente social. Nessa simples inversão, entretanto, já residem alguns problemas. Ao descrever a classe operária como a mediação que faltava à filosofia clássica para chegar ao método correto de compreensão, Lukács encontrou dificuldades em lidar com a consciência de classe tal como se apresentava na realidade. Daí é possível compreender por que Lukács reconhece em poucos momentos de seu livro o fato de que os trabalhadores pudessem estar enredados em formas burguesas de consciência em um momento de crise do capitalismo. A abolição da divisão entre ser e pensar, programa de Lukács para superar as antinomias do pensamento burguês, só poderia efetivar-se no interior de sua teoria por meio de uma identidade entre pensamento e realidade no curso de sua progressiva determinação, assim como no progresso da consciência proletária.

Essa identidade fundamenta a questão da consciência de classe em Lukács, com base na distinção entre a experiência individual e a da classe como um todo. Por um lado, não seria possível que o indivíduo chegasse a apreender as medições necessárias para a visão do todo, uma vez que ele está preso de forma imediata nas malhas da reificação. Por outro lado, somente a classe poderia alcançar essa visão da totalidade, já que ela mesma constitui uma totalidade em si. Ao indivíduo restaria no máximo vislumbrar leis abstratas e parciais a respeito do funcionamento do capitalismo. De maneira correlata, seria impossível encontrar o concreto, atribuição fundamental da totalidade, no indivíduo empírico e histórico. "Estudo concreto significa, portanto: relação com a sociedade como totalidade" (Lukács, 2003: I40), afastando-se do que Lukács chama de consciência psicológica da classe, mera soma ou média do que seus componentes individuais pensam ou sentem. Se o acesso à totalidade depende do uso correto das mediações, então só uma consciência atribuída, adjudicada, poderia mediar classe e conhecimento do todo social, uma vez que o indivíduo concreto é incapaz de tal uso. Não espanta, pois, que o autor tenha atribuído ao partido o papel de portador da consciência de classe.

Na leitura de História e consciência de classe, podemos ver como Lukács oscila entre as possibilidades de formação da consciência de classe. ${ }^{13} \mathrm{Em}$ princípio, ele não quis redundar em uma mitologia ao atribuir a consciência de classe a uma forma imediata de consciência, "uma enigmática consciência genérica (tão enigmática como o 'espírito do povo', de Hegel), cuja relação com o efeito sobre a consciência do indivíduo é completamente incompreensível 
por meio de uma psicologia mecânico-naturalista, aparece então como demiurgo do movimento" (Lukács, 2003: 349). Lukács, porém, não conseguiu evitar em seu livro o aporte do partido bolchevique, na tentativa de explicar precisamente o surgimento da luta política para além da mera existência da classe. Apenas o desenvolvimento histórico e político do proletariado poderia garantir que a "intenção voltada para a totalidade" não permanecesse na apreensão imediata das relações sociais estruturantes.

Se tivermos em conta os comentários de Horkheimer sobre Hegel, a argumentação de Lukács pode ser vista como uma remissão à doutrina da identidade, criticada pelo diretor do Instituto de Frankfurt, em cuja concepção de materialismo ignorar a concretude da existência dos indivíduos significava grave equívoco. Ora, a doutrina da identidade hegeliana entre sujeito e objeto seria pensada enquanto uma unidade de contradições, antecipada desde o início pelo sujeito que tudo abarca, distinguindo realidade efetiva e mera existência casual e aparente, o que pode ser estendido ao problema da identidade na obra lukácsiana. Sem ter de recusar a pretensão de abarcar o real, o pensamento da identidade descarta o que considera uma "existência baixa" - e do mesmo modo Lukács rejeita a "consciência empírica e psicológica" dos proletários por ser imediata. Assim como a classe em Lukács tem a primazia em relação a seus membros individuais por se constituir em uma totalidade, em Hegel a "determinação (Bestimmung) do particular cumpre-se no destino do universal; a essência, o conteúdo substancial do indivíduo não se manifesta nas suas ações individuais, mas na vida do todo ao qual pertence" (Horkheimer, I 999: I22). Com base nisso, é possível dizer que a classe recebe estatuto semelhante ao do Espírito hegeliano em História e consciência de classe, pois Lukács procurou mostrar como o indivíduo é incapaz de perceber as reais determinações da sociedade capitalista, ao contrário da classe enquanto totalidade. Por sua vez, Horkheimer ressalta como o desenvolvimento do Espírito na filosofia hegeliana "se completa independentemente do fato de que os indivíduos, no seu modo de agir histórico, o conheçam e o desejem; este tem sua própria lei" (Horkheimer, I999: I 23). Ou seja, considerando a teoria lukácsiana, seria preciso que os indivíduos reconhecessem no partido, de maneira semelhante ao Estado e à cultura, uma instância superior e definidora de sua realidade, tal como o espírito de um povo, que "muda de um aglomerado de particularidades para um poder metafísico" (Horkheimer, I990: I6).

Não se trata, porém, de imputar à obra de Horkheimer uma espécie de "anti-hegelianismo". Marx é visto por ele simultaneamente como herdeiro e destruidor do legado de Hegel, o que permitiu que as ideias e conteúdos mais frutíferos do método hegeliano ganhassem vida, assim como Lukács pensava. O próprio Horkheimer afirmou em seu discurso de posse que a filosofia social encontrara seus resultados mais brilhantes e consequentes no sistema hegeliano (Horkheimer, I999: I2 I). Mas, ao contrário da influência decisiva que He- 
gel impôs sob o autor húngaro, seria preciso considerar o "método dialético como tal, [...] [em] que permanece como seu fruto apenas o detalhe [...] que se apresenta apenas como o saber de determinados homens efêmeros" (Horkheimer, 20I2b: 30I).

Já vimos que o próprio Lukács reconheceria mais tarde as dificuldades que a influência hegeliana trouxe a sua perspectiva no início dos anos I920, especialmente à concepção do proletariado enquanto sujeito-objeto da história. No prefácio de I967 para História e consciência de classe, ele afirma que a indistinção entre "objetivação" e "alienação" levou a obra a uma série de equívocos que mais tarde fariam a fortuna do livro. A superação dessa indistinção viria somente após detalhada leitura de Manuscritos econômico-filosóficos, texto ainda não publicado na época da primeira edição de seu livro. Contudo, a despeito da importância da avaliação de Lukács, sugerimos que o texto de Marx mais apropriado para se contrapor à leitura lukácsiana de I923 não seria exatamente o dos manuscritos de I844, mas outra obra incompleta de Marx publicada postumamente, A ideologia alemã. É o que se pode depreender da leitura dos ensaios de Horkheimer no início dos anos I930. Dessa forma, o então diretor do Instituto de Frankfurt retoma de maneira particular a crítica ao idealismo dos jovens hegelianos feita por Marx, procurando contestar e superar alguns dos dilemas encontrados nos ensaios lukácsianos. ${ }^{\text {I4 }}$

A ressonância que o texto encontrou nos trabalhos da teoria crítica nos anos I930 é percebida a partir de uma comparação entre aquele trabalho e o discurso proferido por Horkheimer em sua posse como diretor do Instituto de Frankfurt. Vejamos o seguinte trecho da obra de Marx e Engels:

O fato, portanto, é o seguinte: indivíduos determinados [em determinadas relações de produção], que como produtores atuam de um modo também determinado, estabelecem entre si relações sociais e políticas determinadas. É preciso que, em cada caso particular, a observação empírica [que se atém simplesmente aos fatos reais] coloque necessariamente em relevo - empiricamente e sem qualquer especulação ou mistificação - a conexão entre estrutura social e política e a produção (Marx \& Engels, I984: 35, colchetes da edição brasileira).

Por sua vez, Horkheimer enfatizava que tomar a economia como a única e verdadeira realidade, sendo a psique dos homens e sua personalidade meras imagens que espelham a economia, "seria um Marx abstrato e por isso mal interpretado" (Horkheimer, I999: I 30). As dúvidas de Horkheimer quanto à validade das categorias de Lukács em torno da relação entre trabalhadores e reificação encontrariam expressão no projeto de investigação acerca do estado concreto da classe, por meio de pesquisas empíricas. O "trabalho de pesquisa concreto sobre o objeto" teria por objetivo justamente superar os problemas relativos ao tipo de visão que joga todo o destino dos indivíduos em estruturas suprapessoais (Horkheimer, I999: I27). Em particular, a pesquisa feita com operários e trabalhadores de escritório alemães entre I929 e I932 procurou esta- 
belecer correspondências entre os diferentes estratos da classe trabalhadora alemã, suas atitudes políticas e estruturas de personalidade. Seu resultado mais importante foi mostrar que existiam atitudes autoritárias em um número significativo de trabalhadores. ${ }^{15}$

Desse modo, o saber, incluindo o método dialético aventado por Lukács, deveria ceder terreno ao conhecimento do particular e abandonar suas pretensões de se tornar absoluto. Um conceito como o de "consciência adjudicada" não seria condizente com ele, posto que, se existe algo como uma consciência proletária, ela deveria ser buscada nos trabalhadores reais e nas suas reais relações de classe e produção, e não por meio de uma suposta racionalização e hipóstase. Quando Lukács coloca as considerações sobre a história concreta em segundo plano, acaba por agir metafisicamente, retornando a uma posição já criticada por Marx. A certa altura de seu ensaio sobre a reificação, Lukács tenta explicar o conceito de mediação: "Pois 'o mediador', segundo as palavras de Hegel, 'teria de ser aquele em que os dois lados fossem apenas um, em que, portanto, a consciência reconhecesse um dos seus momentos no outro, seu fim e sua ação no destino, e seu destino em seu fim e em sua ação, sua própria es sência nessa necessidade'" (Lukács, 2003: 320, grifos originais). Não surpreende o fato de que Lukács retome esse trecho da obra de Hegel, pois já vimos como a identidade entre sujeito e objeto é fundamental em suas considerações a respeito da tarefa histórica do proletariado. Em seu texto acerca do problema da metafísica em Hegel, Horkheimer faz uma afirmação sobre a filosofia da identidade hegeliana que é apropriada também à construção lukácsiana do proletariado como sujeito-objeto:

A identidade tem de ser pensada como unidade conceitual das contradições, de cuja superação ela resulta, isto é, como o sistema filosófico universal unitário com toda a riqueza de seu conteúdo. Mas a doutrina da identidade absoluta do sujeito e do objeto encontra-se segura desde o início e constitui por toda parte o ponto de mira. Somente por isso as diferenças e tensões podem ser reinterpretadas nesta filosofia como "contradições", porque já de antemão são concebidas como pensamentos do sujeito que tudo abarca e a todas elas são idênticas (Horkheimer, 20I2b: 297).

Além disso, é possível atentar para outro aspecto paralelo às leituras hegeliana e lukácsiana da história a partir dos textos de Horkheimer. Em sua forma mais avançada, representada por Hegel, o idealismo alemão entendeu que o todo coletivo no qual vivemos é essencial na compreensão do ser humano, já que o destino dos homens, que não são meros indivíduos, é dado pelo fato de eles serem membros de uma comunidade. De fato, ele só poderia ser entendido se se levassem em conta "estruturas ontológicas mais amplas que pertencem somente a um todo suprapessoal, [e] que possam ser descobertas apenas na totalidade social" (Horkheimer, I999: I 22). Uma visão materialista da realidade social, porém, não se poderia deter nesse ponto, erro que pode ser atribuído a Lukács. Seria necessário um passo seguinte, superando as aporias 
do pensamento hegeliano. $\mathrm{O}$ aprofundamento do reexame da obra marxiana, à luz de sua relação com a filosofia hegeliana, se fazia mais do que necessário.

Uma das principais teses de Marx contra os jovens hegelianos de sua época consistia em mostrar que "os pressupostos de que partimos não são arbitrários, nem dogmas. São pressupostos reais de que não se pode fazer abstração, a não ser na imaginação. São os indivíduos reais, sua ação e suas condições materiais de vida, tanto aquelas por eles já encontradas como as produzidas por sua própria ação. Esses pressupostos são, pois, verificáveis por via puramente empírica" (Marx \& Engels, I984: 26-27). Por sua vez, Horkheimer procurou mostrar que um dos principais problemas da obra hegeliana estaria na constante transfiguração que realiza, a partir da qual se explicava a vida do indivíduo por meio da vida dos povos e do Estado, e não em referência a sua vida cotidiana e efetiva. Para esse tipo de filosofia "a verdadeira essência do homem não existe na mera interioridade e no destino factual dos indivíduos finitos [...]. [É] na história universal [que reside] essa essência substancial" (Horkheimer, I999: I 24). Assim, o sofrimento do indivíduo foi considerado irrelevante, já que o curso de sua história não é fruto de suas livres decisões.

Precisamos levar em conta, porém, que se a história e o Estado no seu devir exterior sempre emergem do "formigar do arbítrio", se o historiador empírico tem que se ocupar de uma sequência de sofrimento e morte, de estupidez e infâmia, se a existência finita perece sob tormentos indescritíveis e se a história pode ser comparada a um "matadouro, ao qual foram conduzidos ao sacrifício a felicidade dos povos, a sabedoria dos Estados e a virtude dos indivíduos", a filosofia nos eleva acima desse ponto de vista do observador empírico. [...] Segundo Hegel, o indivíduo finito só pode adquirir consciência conceitual de sua liberdade no Estado, através da especulação idealista. Nessa função mediadora Hegel viu essencialmente o engenho (Leistung) da sua filosofia e, portanto, da filosofia em geral, identificando-a com aquela transfiguração do real "que parece injusto" (Horkheimer, I999: I23-I24).

Se entendermos aqui que os termos da crítica a Hegel caberiam aos ensaios e conceitos de Lukács, as ideias de proletariado como sujeito-objeto e como a classe quase destinada a conhecer a totalidade são colocadas em xeque pelo projeto inicial da teoria crítica. Daí que a realização de uma pesquisa a respeito da situação dos trabalhadores na Alemanha no início dos anos I930 se tivesse mostrado essencial no percurso da teoria crítica, devendo levar em conta a maneira como a vida daqueles indivíduos realmente se efetivava, o que significava "evitar decididamente todo tipo de transfiguração" (Horkheimer, I999: I32).

De fato, nessa fase de seu percurso intelectual, Horkheimer aceitava a tese lukácsiana de que o proletariado constituiria o lugar privilegiado na sociedade capitalista para seu conhecimento e transformação. O problema para Horkheimer não estava na própria posição do proletariado diante da teoria, já que ela constitui a seu ver a fonte do marxismo. Como ele afirma em Dämmerung, "as forças dirigidas à criação de um mundo mais humano estão encarnadas na 
teoria e na práxis de pequenos grupos do proletariado" (Horkheimer, 20 I 2c: 442). A questão reside em tomar um dever-ser, como uma identidade absoluta, por algo que é ou possa ser real. Tratava-se de não erigir uma entidade ideal, a consciência de classe, enquanto ponto futuro das aspirações revolucionárias, de negar, portanto, uma teleologia a respeito dessa consciência. Embora Horkheimer reconhecesse a classe como âmbito determinante da vida dos indivíduos, isso não implicaria que o conhecimento das instâncias psicológicas e, portanto, individuais, não fizessem sentido, pelo contrário. Por meio desse exame seria possível apontar qual seria o estado atual da consciência de classe, ou seja, mostrando como de fato os trabalhadores estavam longe de superar a reificação. Um trecho de "História e psicologia" merece atenção especial, por mostrar que, embora a luta de classes seja o motor da história, não se deveria elevar a classe a uma espécie de entidade metafísica: "Quando o antagonismo entre as forças sociais humanas crescentes e a estrutura social, que neste contexto mostra ser o motor da história, substitui as análises concretas como esquema de construção universal, ou quando ele é alçado a um poder necessário à formação do futuro, então o conceito [marxista] de história ora esboçado pode converter-se numa metafísica dogmática definitiva" (Horkheimer, I990: I9).

As reflexões de Horkheimer a partir da recepção das teses de A ideologia alemã podem ser encontradas também em uma resenha sobre o livro de Karl Mannheim, Ideologia e utopia. "Um novo conceito de ideologia?" recupera algumas noções da obra de Marx e Engels, contrapondo sua conceitualização a respeito da ideologia com as teses mannheimianas, além de oferecer elementos que permitem complementar a crítica do frankfurtiano a Lukács. ${ }^{16}$ Publicado pela primeira vez em I929, o texto de Mannheim recupera noções centrais do marxismo, como "ideologia" e "consciência de classe", para lançar as bases de uma sociologia do conhecimento. De forma resumida, a obra observa que, uma vez que não existe uma verdade objetiva, mas verdades que resultam de um ponto de vista particular, a tarefa da sociologia do conhecimento consistiria em mostrar a parcialidade de todas essas formas de pensamento, o que, para o autor, caracterizaria o conceito "total" de ideologia. Esse teria sido formulado originalmente na obra de Marx por meio do conceito de consciência de classe, uma vez que pela primeira vez a estrutura da sociedade e suas correspondentes formas intelectuais começaram a ser compreendidas como variantes, de acordo com as relações entre as classes sociais. Para Mannheim, contudo, seria necessário dar um passo além, pois a crítica ideológica deveria ser estendida a todas as classes e todos os grupos sociais, incluindo a classe trabalhadora e os marxistas. Assim, o marxismo não constituiria posição privilegiada para o conhecimento da realidade social. A próxima etapa consistiria em obter uma síntese dos vários pontos de vista, o que permitiria maior aproximação da verdade objetiva. Posto que todos eles são essencialmente limitados, seria preciso reconstruí-los e reuni-los em uma totalidade, superando as barreiras de cada um desses pontos de vista. 
O exame da ideologia em Mannheim, porém, acaba por se afastar completamente da noção de falsa consciência para se aproximar de considerações de cunho metafísico. Para o autor, haveria uma base comum às diferentes visões de mundo e seu exame aprofundado diante da história e das posições sociais, isto é, existiriam juízos metafísicos e metaempíricos que sustentariam a compreensão dos pressupostos do pensamento humano em suas mais diversas manifestações. Nesse sentido, o desenrolar da história seria uma espécie de matriz dentro da qual a natureza humana encontraria expressão. O desenvolvimento de uma sociologia do conhecimento nesses moldes permitiria, portanto, não apenas a reconstrução de uma totalidade de pontos de vista, mas também algo mais elevado, o conceito das características mais essenciais do devir humano. Essa ideia mais geral, que atravessa toda a argumentação de Mannheim, seria o alvo privilegiado da crítica de Horkheimer.

Ao formular um conceito "total" de ideologia, Mannheim não recorre aos homens concretos, dotados de interesses, mas, conforme Horkheimer, a "um 'sujeito de atribuição' (Zurechnungssubjekt), isto é, uma atitude cognitiva ideal que corresponde, quanto ao sentido, à posição de um grupo dentro da respectiva sociedade. [...] A cada grupo corresponderia um conjunto de pensamento" (Horkheimer, 2012a: 272 e 274). Aqui, o termo atribuição, ou adjudicação, é o mesmo utilizado por Lukács para se contrapor à "consciência psicológica". Em certa passagem de Ideologia e utopia, Mannheim chega a formular o problema da consciência individual quase nos mesmos termos presentes em História e consciência de classe: "Os membros individuais da classe operária, por exemplo, não experimentam todos os elementos de um horizonte que se poderia chamar de Weltanschauung proletária. Cada indivíduo participa apenas em determinados fragmentos deste sistema de pensamento, cuja totalidade não é de forma alguma a simples soma destas experiências individuais fragmentárias" (Mannheim, I972: 84). ${ }^{\text {I7 }}$ Há um paralelismo entre a noção mannheimiana de que as formas parciais de consciência social deveriam ser reconstruídas em um todo artificial e a noção lukácsiana de consciência adjudicada, que também deveria superar os limites da consciência proletária imediata. A grande crítica de Horkheimer a Mannheim, e por extensão a Lukács, consiste em mostrar como a consciência de classe, sobretudo a consciência adjudicada, se constrói tendo por referência uma verdade absoluta, ao contrário de suas intenções. Seus esforços remetem à metafísica do idealismo alemão, distorcendo a tarefa que o próprio Marx havia posto. "A intenção de sua ciência não era o conhecimento de uma 'totalidade' ou de uma verdade total e absoluta, mas a modificação de determinadas condições sociais" (Horkheimer, 201 2a: 27I).

Trazendo de volta as palavras de Marx em A ideologia alemã, Horkheimer critica a falta de vínculo com a realidade material que os conceitos de Mannheim apresentam: "Marx queria com razão eliminar a convicção de que haveria um ser que domina as épocas e as sociedades e que lhes conferiria sentido. 
Precisamente esse traço da filosofia hegeliana lhe parecia uma ilusão idealista. Apenas os próprios homens - e não a 'essência' homem, mas os homens reais de um momento histórico determinado, dependentes uns dos outros e da natureza interna e externa - são os sujeitos ativos e passivos da história" (Horkheimer, 20I 2a: 282). Já vimos como Marx contrapunha a noção de uma investigação empírica às formulações do idealismo alemão. Em Horkheimer, essa noção tem um sentido bem específico, ligeiramente distinto da concepção marxiana. Enquanto Marx lutava contra as concepções neo-hegelianas - seus representantes imaginavam que o combate aos "erros" do mundo se daria no plano das ideias, que os limites da sociedade seriam os limites da consciência -, Horkheimer tinha a sua frente uma concepção materialista de classe, mas que recaía no idealismo já criticado por Marx, isto é, a concepção lukácsiana. Assim, pode-se dizer que foi preciso atualizar a crítica marxista, tomando à letra a expressão marxiana em relação aos neo-hegelianos: "As frases ocas sobre a consciência cessam, e um saber real toma seu lugar. [...] abstrações, separadas da história real, não possuem valor algum" (Marx \& Engels, I984: 38). É possível apreender desses comentários uma crítica subentendida aos pressupostos de Lukács acerca de sua concepção de classe, pois ele não conseguia deixar de referir a consciência a um reino das ideias, por mais que a ancorasse em uma instância política, como o partido político. Assim como o idealismo alemão, sobretudo a partir de Hegel, amparava-se sobre uma filosofia da história que redundaria na constituição de um espírito absoluto, a posição ocupada pela consciência de classe em Lukács também revela uma construção similar, se atentarmos para os comentários críticos de Horkheimer em seus textos do início da década de i 930.

As dificuldades encontradas diante das reais condições da consciência de classe, transparecidas pela questão da "consciência psicológica", significaram, no limite, o enfraquecimento do método marxista, desconsiderando a situação concreta das classes trabalhadoras. Em comentário a respeito da sociologia de Mannheim, mas que também caberia à construção lukácsiana da consciência de classe, o diretor do Instituto de Frankfurt afirmou que ela "busca 'correspondências de forma' entre a posição social e a totalidade das visões de mundo concebidas aproximadamente no sentido de um 'tipo ideal'", sem recorrer à situação social de seus portadores (Horkheimer, 20I 2a: 287). Não levar em conta o modo como os seus sujeitos de fato pensavam implicava não reconhecer como a ideologia e a reificação operavam no interior da classe. "É evidente que, em todos estes casos, estas representações são a expressão consciente - real ou ilusória - de suas verdadeiras relações ou atividades, de sua produção, de seu intercâmbio, de sua organização política e social. A suposição oposta é apenas possível quando se pressupõe fora do espírito de indivíduos reais, materialmente condicionados, um outro espírito à parte" (Marx \& Engels, I984: 36). Nesse sentido, os textos de Horkheimer ajudam a refletir como Lukács acabou por incorrer em contradições. Com as condições nas quais se encontrava a 
classe operária europeia após as derrotas nas décadas de I920, as abstrações de cunho hegeliano possibilitariam encontrar um refúgio para os impasses históricos. De acordo com Horkheimer, o marxismo deveria ir além de uma noção abstrata de "correspondência" entre situação social e consciência de classe.

\section{CONSIDERAÇÕES FINAIS: A REPRODUÇÃO DA VIDA DOS HOMENS PARA ALÉM DA BASE E DA SUPERESTRUTURA}

As reflexões críticas de Horkheimer acerca das questões postas por Lukács em História e consciência de classe representaram o ponto de partida das pesquisas empíricas levadas a cabo pelo Instituto de Pesquisa Social no início dos anos I930. Embora contenham muitos problemas, tanto na formulação das questões quanto em sua execução, elas foram cruciais para que o projeto de renovação do marxismo continuasse de pé, solidificando o modelo analítico da teoria crítica. Mais do que isso, porém, é preciso dizer que esse modelo permaneceria ao longo da trajetória da teoria crítica, mesmo em um livro que supostamente se tenha convertido a uma simples filosofia da história, Dialética do esclarecimento. ${ }^{18}$ Evidentemente, não se trata de dizer que não houve mudanças substanciais no diagnóstico da teoria crítica entre as décadas de i930 e I940. Contudo, a releitura dos temas lukácsianos por meio das categorias de A ideologia alemã, tal qual o esforço empreendido por Horkheimer, resultaria numa reformulação radical do binômio "base-superestrutura". Essa reformulação, e até mesmo superação, pode mostrar-se uma chave de leitura dos trabalhos da teoria crítica depois de I940, especialmente do trabalho conjunto de Horkheimer e Adorno.

Como se sabe, a bibliografia já destacou a mudança de significado daquele binômio por parte de Horkheimer, que trouxe à tona a importância dos aspectos psicológicos e culturais na conformação do capitalismo. ${ }^{19}$ Diferentemente de seu antecessor, Carl Grünberg, que seguia os preceitos básicos da ortodoxia marxista tanto em sua versão socialdemocrata quanto comunista - a superestrutura refletiria, de maneira mais ou menos direta, a base material da sociedade - Horkheimer acreditava que a questão não se apresentava de maneira tão simples. Se a ordem social "condiciona não só as instituições políticas e jurídicas, mas também as ordens mais altas da cultura”, pressupor uma correspondência constante entre os processos ideais e materiais não dá a devida atenção ao complexo papel mediador dos elementos psíquicos. "Se aprendermos, com a psicologia, que a satisfação das necessidades é uma realidade psíquica que em intensidade não deve ser inferior aos prazeres materiais, então muito se ganhará para a compreensão de uma série de fenômenos históricos" (Horkheimer, I990: 25).

Em meio a esses fenômenos históricos estava a encruzilhada em que se encontrava a classe trabalhadora, colocada entre a possibilidade da revolução socialista e a aceitação das formas mais brutais da sociedade capitalista, com as ditaduras fascistas. A questão do consenso e da coerção entre os proletários 
começa a se delinear nos textos de Horkheimer, e seria mais bem explorada nos anos seguintes. Já no prefácio à primeira edição da revista do Instituto, Horkheimer afirmava que entre os problemas da pesquisa social encontram-se cada um dos âmbitos culturais e as leis que estão envolvidas em suas mudanças (Horkheimer, 2009: 37). Essa mudança na postura quanto ao papel da superestrutura possibilitaria ao autor deslindar seu diagnóstico sobre a classe operária alemã, além de alterar o rumo e os problemas considerados pelo Instituto, mostrando como o marxismo deveria levar em conta os fatos que se opuseram às expectativas revolucionárias do período.

A peça fundamental nessa reconstrução encontra-se justamente na leitura que Horkheimer fez de A ideologia alemã, sobretudo quando se tem em vista um trecho sobre a reprodução da vida dos homens como base de uma investigação materialista, que sintetiza as considerações de Marx e Engels a respeito do funcionamento das relações sociais:

O modo pelo qual os homens produzem seus meios de vida depende, antes de tudo, da natureza dos meios de vida já encontrados e que têm de reproduzir. Não se deve considerar tal modo de produção de um único ponto de vista, a saber: a reprodução da existência física dos indivíduos. Trata-se, muito mais, de uma determinada forma de atividade dos indivíduos, determinada forma de manifestar sua vida, determinado modo de vida dos mesmos. Tal como os indivíduos manifestam sua vida, assim são eles. O que eles são coincide, portanto, com sua produção, tanto com o que produzem, como o modo como produzem. O que os indivíduos são, portanto, depende das condições materiais de sua produção (Marx \& Engels, I984: 27-28, grifos originais).

Trata-se de dizer que a própria ideia de uma relação entre base e superestrutura já possuía desde o início da teoria crítica um lugar reduzido. Em vez de uma separação estanque entre os domínios da vida social, pelos quais comumente se entende aquele binômio, trata-se na verdade de observar as constantes interdependências entre eles. Se as relações sociais estruturantes do capitalismo são o ponto de partida necessário da crítica, isso não significa, porém, que o acesso a seu conhecimento se dê única e exclusivamente na economia. Daí que a ideia de uma investigação materialista a partir da maneira como os indivíduos produzem e reproduzem sua vida tenha uma posição privilegiada nas considerações de Horkheimer e de outros membros da teoria crítica. A fecundidade de suas análises tem como ponto de partida essa profunda reconsideração da teoria marxista. Graças a ela, a teoria crítica pode compreender em que medida as transformações no capitalismo levaram a novas modalidades de dominação social e exploração.

A título de ilustração, pense-se no conceito de indústria cultural. ${ }^{20} \mathrm{Se}$ Horkheimer e Adorno vissem os fenômenos culturais apenas como um epifenômeno da base econômica da sociedade, seria impossível que eles considerassem a maneira como tais fenômenos passaram a estar intrinsecamente ligados à reprodução das relações sociais capitalistas. Ao mobilizar a questão da 
cultura em sua análise, os autores da Dialética do esclarecimento estavam bastante atentos a essa aparente contradição entre base material, sem a qual a cultura não pode existir, e o modo como essa base se mostrou um elementochave nas novas determinações que a reprodução da totalidade social tomou no século XX. Com a paulatina concentração do capital, a arte passou a constituir importante mediação da reprodução do capital, já que seria possível, ao menos no início, fugir das determinações impostas pela concorrência capitalista. Ela, contudo, se transformou não só em um campo de investimento. A ampliação da reprodução social fez com que a cultura se tornasse um meio especial para que os indivíduos aceitassem a constituição da sociedade enquanto tal.

É preciso, no entanto, evitar chamar de "fixação da superestrutura" (Bonß, Schindler, I982: 49) esse desenvolvimento da teoria crítica. O que os autores de Dialética do esclarecimento tinham em vista, e Horkheimer desde o início dos anos I930, não era apenas um conceito "expandido" de cultura, isto é, "formas dialeticamente mediadas de reflexão" de interesses econômicos, em contraposição ao marxismo positivista da Segunda Internacional (Dubiel, I982: 462). ${ }^{21}$ Ao criticar o hegelianismo de Lukács por descartar a consciência empírica e psicológica dos trabalhadores, Horkheimer não construiu apenas um modelo de materialismo com base nas considerações da psicanálise, vista em princípio como disciplina auxiliar da economia, ou um modelo de análise centrado exclusivamente na cultura. Entender o percurso da teoria crítica essencialmente dessa forma significaria justamente perder de vista a complexidade de seu diagnóstico "econômico" e "político". De fato, importava ao autor compreender a maneira como os diferentes âmbitos da vida social mediavam-se dialeticamente, mas tendo em vista, sobretudo, em que medida o domínio das relações capitalistas se reafirmava. Só esse modelo poderia fazer perceber, aos poucos, é verdade, o fato de que a ruptura com essa forma social teria de ser completa, sob o risco de ininterrupta recaída na barbárie. Dessa forma, o desenvolvimento da teoria crítica nesse período procurou radicalizar a tese, marxiana e lukácsiana, do domínio das relações sociais baseadas no trabalho abstrato. Ser totalizante não seria a intenção da teoria crítica, mas a própria essência das relações de dominação e exploração. Entender que o marxismo tenha como eixo fundamental apenas as relações econômicas significa, no limite, desconsiderar que a reificação tende a se espraiar por todo o tecido social. Não chega a ser espantoso, portanto, que essa visão considere a sociedade a partir de esferas que guardariam um potencial de resistência frente à lógica da forma mercadoria.

Recebido em I5/og/20I5 | Revisto em 30/07/2016 | Aprovado em I3/o9/2016 
FILOSOFIA DA HISTÓRIA OU REPRODUÇÃO DA VIDA DOS INDIVÍDUOS?

256

Vladimir Puzone é doutor em sociologia pela Universidade de São Paulo (USP), com estágio de pesquisa na Technische Universität Berlin, na Alemanha. Atualmente é pesquisador no Departamento de Sociologia da Universidade de Brasília (UnB), vinculado ao Programa Nacional de PósDoutorado da Capes. É autor de Capitalismo perene: reflexões sobre a estabilização do capitalismo a partir de Lukács e da teoria crítica (2016). 


\section{NOTAS}

I A respeito da centralidade do conceito de reificação para a teoria crítica nos anos 30, cf. Feenberg (I98I, especialmente p. I33-200). Com relação ao conceito de totalidade e sua influência não apenas para a teoria crítica, mas para os diversos autores do marxismo ocidental, cf. Jay (I986, sobretudo p. 8I-I27 e I96-275).

2 Sigo aqui o relato de Douglas Kellner (I984: 40) em uma conversa pessoal com Marcuse.

3 De acordo com Silva (20 I I: 42), o "pensamento do jovem Lukács influenciou os primeiros escritos de Horkheimer da década de I930 tanto pela aceitação de alguns de seus aspectos quanto pela recusa de algumas de suas teses".

4 Por meio do conceito de reificação, Lukács criticava as concepções dos socialdemocratas do início do século XX, que aproximariam uma parcela dos trabalhadores às formas burguesas de consciência, impedindo qualquer transformação radical da sociedade capitalista. "Com a ideologia socialdemocrata, o proletariado recai em todas as antinomias da reificação" (Lukács, 2003: 390). A respeito dos acontecimentos na Alemanha durante o período em que Lukács redige seus ensaios e que redundariam no fracasso da revolução socialista, cf. Loureiro (2005).

5 Em seu livro de aforismos intitulado Dämmerung, Horkheimer faz uma série de considerações sobre a situação da classe trabalhadora alemã entre os anos I920 e o início da década de I930, especialmente em "A impotência da classe operária alemã". Nesse texto curto, o autor aponta para uma divisão das classes trabalhadoras alemãs devastadas pela crise econômica que o país vivia: de um lado, estariam os trabalhadores industriais e empregados, apoiadores das políticas reformistas da socialdemocracia, e, de outro, os desempregados, que ajudavam a formar as fileiras do partido comunista. Essa divisão seria prejudicial, pois "a solidariedade dos interesses do proletariado sofre perdas cada vez mais" (Horkheimer, 20I2C: 374). Ao mesmo tempo, os desempregados também constituiriam parte das massas nazistas. Preferimos utilizar aqui o título original em alemão, que pode ser vertido para “crepúsculo", já que ainda não está disponível uma tradução do texto para o português. 
6 De acordo com Michiel Korthals (I985: 32I), Horkheimer conhecia muito bem os textos de Lukács. Em comparação com Marcuse, porém, ele os citava menos do que seu colega e os avaliava de maneira muito mais negativa.

7 O outro autor a quem Horkheimer faz referência é Ernst Bloch, que também marcou o marxismo da época com seu livro 0 espírito da utopia, publicado pela primeira vez em I9I8.

8 Lukács identificou o problema por meio do conceito de "crise ideológica", que se refere ao fato de que "em meio à crise fatal do capitalismo, amplas massas do proletariado vivenciam o Estado, o direito e a economia como o único meio possível de sua existência" (Lukács, 2003: 475). No entanto, segundo Mészáros (2002: 388), o autor de História e consciência de classe não teria reconhecido que o capitalismo da época encontrara meios materiais para sustentar sua estabilização, bem como a adesão de vastas parcelas das classes trabalhadoras ao reformismo. Assim, restaria como saída explicar esse fenômeno por meio de fatores ideológicos.

9 Não seria descabido dizer que Lukács não era um marxista ortodoxo, mas sim heterodoxo, já que procurou afastar-se dos modelos teóricos da Segunda Internacional. Por isso mesmo, ele afirmava que ortodoxia significava simplesmente ater-se ao método marxista, desenvolvendo-o e aperfeiçoando-o, e não ver as obras de Marx como uma verdade intemporal, interpretando-a de maneira escolástica, como muitos fizeram na época, entre eles Eduard Bernstein. Cf. Lukács (2003: 63-64).

Io A redução de seus estatutos teóricos a um mesmo denominador não exclui as diferenças gritantes, tanto a respeito do entendimento da teoria de Marx e sua validade nas condições históricas de então quanto às respectivas linhas partidárias. Trata-se de ressaltar, no entanto, um aspecto comum a ambas. Cf. Korsch (2008: 83-I22).

I I Certamente, os regimes nazifascistas não contaram com apoio total das classes trabalhadoras, já que houve ao mesmo tempo resistência por parte delas e repressão intensa sobre suas organizações por parte dos governos autoritários. No entanto, o fato que deveria ser explicado, e que se tornou parte das tarefas do Instituto de Pesquisa Social, 
era entender como poderia haver trabalhadores que apoiavam esses regimes. Para uma problematização histórica a respeito do misto de resistência e repressão na Alemanha hitlerista, cf. Mason (I996).

I 2 Sigo aqui algumas indicações de Alfred Schmidt (I980: Io*I $\left.2^{*}\right)$, para quem os textos de Horkheimer se afastavam da perspectiva de Lukács e de Korsch - ainda que seus ensaios tivessem como pressuposto o clima renovador do "marxismo ocidental". Sem se aprofundar no tema, Schmidt destaca como Horkheimer procurou se distanciar do dogmatismo representado por um saber histórico-universal total. Nesse sentido, sua posição teórica estaria mais próxima de Marx, em comparação com Lukács e Korsch. De maneira semelhante, Martin Jay (I996: 89-90) também aponta para uma crítica implícita de Horkheimer a História e consciência de classe e sua metafísica hegeliana. De todo modo, os problemas na teoria lukácsiana não invalidam sua importância vital para a teoria crítica, como bem aponta Ricardo Musse (2005: 388) a respeito do peso que a categoria "totalidade" adquiriu com a obra de Lukács: "sob a égide da filosofia da identidade que a categoria da totalidade justifica, em Lukács, o trânsito de mão dupla entre fenômenos objetivos e subjetivos, economia e superestrutura, que se tornará, a partir de então, uma das marcas distintivas do marxismo ocidental".

I3 De acordo com Marcos Nobre (200I: 89-I05), Lukács oscila entre uma concepção luxemburguista de partido, na qual as ações espontâneas da classe teriam lugar privilegiado, e a concepção leninista, com o partido centralizando as ações. Tal oscilação remeteria diretamente ao crescente predomínio da reificação sobre os trabalhadores, o que teria levado Lukács a ver o modelo de partido organizado por Lenin como a medida para o julgamento objetivo das ações a empreender.

I4 Apesar de essa obra de Marx e Engels só ter sido publicada na década de I930, é provável que Horkheimer já tivesse acesso ao texto pelo menos desde 1925, graças à parceria entre o Instituto de Pesquisas Sociais e o Instituto MarxEngels, que cuidava da publicação das obras de Marx - a publicação da primeira versão do texto data de I926. Cf. Abromeit (201 I: I82). 
I5 Embora essa investigação tenha sido feita antes de Horkheimer assumir a direção do Instituto, Abromeit (20I I: 2 I I-226) afirma que ela já consistia em uma aplicação das ideias desenvolvidas pelo autor entre os anos I920 e I930, tanto pela dimensão empírica quanto por sua orientação marxista. De fato, a pesquisa não foi concluída. Tanto os questionários quanto a análise que Fromm realizou a partir dos dados obtidos foram reconstruídos e editados por Wolfgang Bonß. Cf. Fromm (I984).

I6 Jay (I985: 68-9) afirma não apenas que o livro de Mannheim era visto como uma resposta a História e consciência de classe, mas também que a nascente teoria crítica teria tomado para si a tarefa de defender e refinar os argumentos presentes no livro de Lukács, assim como responder ao desafio posto ao marxismo por Ideologia e utopia. De maneira semelhante, Abromeit (20 I I:I44) diz que Horkheimer estaria defendendo Marx e até mesmo Lukács contra sua apropriação feita por Mannheim. Na verdade, gostaríamos de sugerir algo distinto: que a resenha de Horkheimer oferece elementos para complementar sua crítica a Lukács justamente pela proximidade de alguns elementos entre História e consciência de classe e Ideologia e utopia.

I7 Essa semelhança entre as obras não seria casual, já que, segundo Löwy (2000: 84), "Ideologia e utopia é um diálogo (e uma resposta) a História e consciência de classe".

I 8 Essa posição é representada de maneira exemplar pelos comentários de Habermas (201 2: 687-688), para quem a teoria crítica seria marcada pela filosofia da história contida na teoria marxiana do valor, traço reforçado pela virada da obra de Horkheimer nos anos I940: "Os princípios do materialismo histórico, que enfocam a relação dialética entre as forças produtivas e as relações de produção, tinham-se transformado em proposições pseudonormativas sobre uma teleologia objetiva da história. Esta passou a ser tida como força impulsionadora da realização de uma razão que se manifesta de modo ambíguo nos ideais burgueses. E para se assegurar de seus fundamentos normativos a Teoria Crítica não tinha outra saída a não ser uma filosofia da história. Ora, esse terreno era impróprio para um programa de pesquisa empírico".

I9 Bonß \& Schindler (I982: 48-50) oferecem um resumo da questão, enquanto Dubiel (I982) traça um largo panorama 
da relação entre cultura e o binômio base-superestrutura na teoria crítica dos anos i930 e I940.

20 Não há espaço suficiente para desenvolver o assunto, especialmente o exame das novas modalidades de dominação e exploração no desenvolvimento da teoria crítica. Por isso, fazemos referência às ideias de Wolfgang Leo Maar (2000: 5) a respeito do vínculo entre o conceito de indústria cultural e a forma com que a teoria crítica, sobretudo na figura de Adorno, tematizou o processo de reprodução ampliada do capitalismo: "Mais do que propor uma crítica da economia política no plano da indústria cultural, como poderia parecer a alguns intérpretes, Adorno integra a sua apreensão da indústria cultural à crítica da economia política, revelando indústria cultural e semiformação como peças-chave para compor adequadamente os mecanismos pelos quais a acumulação capitalista procura se tornar perene" (grifos originais).

2 I Para uma crítica a respeito do entendimento do conceito de cultura nos atuais representantes da teoria crítica, sobretudo na figura de Axel Honneth, que procura atualizar a reconstrução dessa vertente feita por Habermas, cf. o texto de Sílvio Camargo (2006: I4). A partir de seus comentários sobre o tratamento do conceito de cultura, e que podem ser aplicados, a nosso ver, às dificuldades de comentadores como Dubiel, Bonß \& Schindler, Camargo afirma que um dos principais desafios da atual geração da teoria crítica é lidar com a relação entre cultura e dominação, uma vez que esse elemento se perde na noção de que a cultura seria "o espaço por excelência em que se travam as lutas por identidade [...]. A cultura é assim o ponto a partir do qual compreendemos uma ampla gama de lutas que se travam no atual estágio do capitalismo e que não dizem respeito, em princípio, àquelas lutas de natureza econômica". Dessa forma, o fenômeno da cultura não seria vislumbrado como produtor de riqueza e, consequentemente, de desigualdade. Além disso, e mais importante, o atual estágio da teoria crítica não apresentaria um conceito de capitalismo adequado à atual fase histórica, "furtando-se a uma relação entre trabalho e cultura na sociedade contemporânea, problema ao qual não se pode furtar uma teoria crítica da sociedade". 


\section{REFERÊNCIAS BIBLIOGRÁFICAS}

Abromeit, John. (20I I). Max Horkheimer and the foundations of the Frankfurt School. Cambridge: Cambridge University Press.

Adorno, Theodor W. (2009) [I966]. Dialética negativa. Rio de Janeiro: Zahar.

Adorno, Theodor W. (2003) [1958]. Reconciliación extorsionada. Sobre Contra el realismo mal entendido de Lukács. In: Notas sobre literatura. Madrid: Akal, p. 242-269.

Bonß, Wolfgang \& Schindler, Norbert. (I982). Kritische Theorie als interdisziplinärer Materialismus. In: Bonß, Wolfgang \& Honneth, Axel (orgs.). Sozialforschung als Kritik. Zum sozialwissenschaftlichen Potential der Kritischen Theorie. Frankfurt am Main: Suhrkamp, p. 3 I-66.

Camargo, Sílvio. (2006). Axel Honneth e o legado da teoria crítica. Política e Trabalho. Revista de ciências sociais, 24, p. I 23 - I38.

Dubiel, Helmut. (1982). Die Aufhebung des Überbaus. Zur Interpretation der Kultur in der Kritischen Theorie. In: Bonß, Wolfgang \& Honneth, Axel (orgs.). Sozialforschung als Kritik. Zum sozialwissenschaftlichen Potential der Kritischen Theorie. Frankfurt am Main: Suhrkamp, p. 456-8I.

Feenberg, Andrew. (198I). Lukács, Marx and the sources of critical theory. Totowa: Roman \& Littlefield.

Fromm, Eric. (1984). The working class in Weimar Germany: a psychological and sociological study. Cambridge: Harvard University Press.

Habermas, Jürgen. (20I2) [I98I]. Teoria do agir comunicativo, v. 2. Sobre a crítica da razão funcionalista. São Paulo: Martins Fontes.

Horkheimer, Max. (201 2a) [1930]. Ein neuer Begriff von Ideologie? In: Gesammelte Schriften, v. 2, Philosophische Frühschriften I922-I932. Frankfurt am Main: Fischer, p. 27 I-94.

Horkheimer, Max. (201 2b) [1932]. Hegel und das Problem der Metaphysik. In: Gesammelte Schriften, v. 2. Philosophische Frühschriften I922-I 932. Frankfurt am Main: Fischer, p. 295-308.

Horkheimer, Max. (20I2C). Dämmerung. Notizen in Deutschland (I93I/I934). In: Gesammelte Schriften, v. 2. Philosophische Frühschriften I922-I932. Frankfurt am Main: Fischer, p. 308-452. 
Horkheimer, Max. (2009) [1932]. Vorwort [zu Heft I/2 des I. Jahrgangs der Zeitschrift für Sozialforschung]. In: Gesammelte Schriften, v. 3. Schriften I 93 I - I 936. Frankfurt am Main: Fischer, p. 36-39.

Horkheimer, Max. (I999) [I93I]. A presente situação da filosofia social e as tarefas de um instituto de pesquisas sociais. Estudos marxistas, Praga, 7, p. I 2 I-I 32.

Horkheimer, Max. (I990) [1932]. História e psicologia. In: Teoria Crítica I. Uma documentação. Tomo I. São Paulo: Perspectiva, p. I3-30.

Horkheimer, Max. (I985). Metaphysische Verklärung der Revolution. In: Gesammelte Schriften, v. I I, Nachgelassene Schriften I 9I4-I 93 I. Frankfrut am Main: Fischer, p. 264-266. Jay, Martin. (1996). The dialectical imagination. A history of the Frankfurt School and the Institute of Social Research. I923-I950. Berkley/Los Angeles/London: University of California Press. Jay, Martin. (1986). Marxism and totality. The adventures of a concept from Lukács to Habermas. Berkley/Los Angeles: University of California Press.

Jay, Martin. (1985). The Frankfurt School's critique of Karl Mannheim and the sociology of knowledge. In: Permanent exiles. Essays on the intellectual migration from Germany to America. New York: Columbia University Press, p. 62-78.

Kellner, Douglas. (1984). Herbert Marcuse and the crisis of marxism. Berkley/Los Angeles: University of California Press.

Korsch, Karl. (2008) [1923]. Marxismo e filosofia. Rio de Janeiro: Ed. UFRJ.

Korthals, Michiel. (I985). Die Kritische Theorie des frühen Horkheimer: Mißverständnisse über das Verhältnis von Horkheimer, Lukács und dem Positivismus. Zeitschrift für Soziologie, I4/4, p. 315-329.

Loureiro, Isabel. (2005). A revolução alemã, I 9 I 8-I 923 . São Paulo: Editora Unesp.

Löwy, Michael. (2000). As aventuras de Karl Marx contra o barão de Münchhausen. Marxismo e positivismo na sociologia do conhecimento. São Paulo: Cortez.

Lukács, Georg. (2003) [1923]. História e consciência de classe. Ensaios sobre dialética marxista. São Paulo: Martins Fontes. 
Maar, Wolfgang Leo. (2000). "A produção da sociedade pela indústria cultural". Revista Olhar, 2/3, p. 2-24.

Mannheim, Karl. (I972) [I929]. Ideologia e utopia. Rio de Janeiro: Zahar.

Marx, Karl \& Engels, Friedrich. (1984) [1846]. A ideologia alemã (I - Feuerbach). São Paulo: Hucitec.

Mason, Tim. (1996). The containment of the working class in Nazi Germany. In: Mason, Tim \& Caplan, Jane. Nazism, fascism and the working class. Cambridge: Cambridge University Press, p. 23 I-74.

Mészáros, István. (2002). Para além do capital: rumo a uma teoria da transição. São Paulo: Boitempo.

Musse, Ricardo (2005). A dialética como discurso do método. Tempo Social. Revista de sociologia da USP, I7/I, p. 367-389.

Nobre, Marcos (200I). Lukács e os limites da reificação: um estudo sobre História e consciência de classe. São Paulo: Ed. 34 .

Schmidt, Alfred. (I980). Die Zeitschrift für Sozialforschung. Geschichte und gegenwärtige Bedeutung. In: Zeitschrift für Sozialforschung, v. I. Reimpressão. München: Kösel Verlag, p. 5-63.

Silva, Rafael Cordeiro da. (20I I). Max Horkheimer: teoria crítica e barbárie. Uberlândia: Edufu. 
Palavras-chave

Teoria crítica; marxismo; idealismo alemão; transfiguração; consciência de classe.

\section{Keywords \\ Critical theory; \\ Marxism; \\ German idealism; \\ transfiguration; \\ class consciousness.}

\section{FILOSOFIA DA HISTÓRIA OU REPRODUÇÃO DA VIDA DOS INDIVÍDUOS? A CRÍTICA DE MAX HORKHEIMER A GEORG LUKÁCS E A REFORMULAÇÃO DO MARXISMO}

\section{Resumo}

O exame feito por Max Horkheimer dos pressupostos que aproximaram a teoria lukácsiana da consciência de classe a alguns aspectos do idealismo alemão deu ensejo às formulações da teoria crítica a respeito do funcionamento da sociedade capitalista e da maneira como se deveria abordála. Ao contrário dos textos de Lukács, que terminam por se afastar de um exame das transformações históricas do início do século XX e da real situação das classes trabalhadoras, a teoria crítica coloca no centro das análises os fatores individuais e concretos que levavam as classes trabalhadoras a aceitar a dominação capitalista. Para isso, foi fundamental a releitura de A ideologia alemã, de Marx e Engels. Essa recuperação do texto marxiano permite entender a fecundidade das análises da teoria crítica, contrariando as teses que identificam a primeira fase da teoria crítica com uma filosofia da história.

\section{PHILOSOPHY OF HISTORY OR REPRODUCTION OF THE LIFE OF INDIVIDUALS? MAX HORKHEIMER'S CRITIQUE OF GEORG LUKÁCS AND THE REFORMULATION OF MARXISM}
Abstract
Max Horkheimer's inquiry into the premises that connect the Lukácsian theory of class consciousness to various as- pects of German idealism resulted in critical theory's for- mulations concerning how capitalist society operates and the way in which it should be examined. In contrast to the texts of Lukács, which ended up turning away from an ex- amination of the historical transformations of the start of the twentieth century and the real situation of working classes, critical theory places at the centre of analysis the individual and concrete factors that led the working class- es to accept capitalism domination. To this end, it was es- sential to reread The German ideology by Marx and Engels. This recuperation of the Marxian text allows us to grasp the fertility of critical theory's analyses, contradicting the- ses that identify the first phase of critical theory as a phi- losophy of history. 